\title{
KARAKTERISTIK DESAIN HIB RIDA PADA KOMIK 7 WONDERS KARYA METALU
}

\author{
Fenny Rahmawati Lubis ${ }^{1 *}$, Dwi Budiwiwaramulja ${ }^{2 *}$ \\ Program Studi Pendidikan Seni Rupa Jurusan Seni Rupa Fakultas Bahasa dan Seni \\ Universitas Negeri Medan \\ Jl. Willem Iskandar Pasar V Medan Estate, Kec, Percut Sei Tuan, Kab. Deli Serdang, Kode Pos 20371 \\ Sumatera Utara. Indonesia \\ Email:frahmawatilubis96@gmail.com,medanpro@gmail.com
}

\begin{abstract}
Abstrak
Komik Jepang menjadi salah satu kiblat untuk referensi dalam membuat komik khususnya komik manga. Tidak sedikit komik Indonesia yang sangat kental dengan unsur manga hingga sulit membedakan komikus Jepang dengan komikus Indonesia bila hanya di lihat dari bentuk visualnya. Selain menggarap style gambar manga jepang, tak sedikit komikus-komikus Indonesia yang menghibridakan karakteristik pada desain karakter visual Indonesia. Sepeti pada salah satu komik Indonesia yaitu komik 7 Wonders. Penelitian ini bertujuan untuk mengetahui identitas dari desain karakter visual yang di hibrida pada salah satu komik Indonesia yaitu komik 7 Wonders. Penelitian ini menggunakan pendekatan metode deskriptif kualitatif y aitu dengan menguraikan masing-masing objek yang akan diteliti. Hasil temuan penelitian ini menunjukkan bahwa karakter yang memiliki unsur hibrida paling menonjol adalah pada karakter bidadari 7 Wonders. Desain karakter visual pada karakter tujuh bidadari 7 Wonders telah meng alamideformasi dan pengabungan dua atau lebih identitas visual, baik pada busana maupun pada karakter figurnya. Identitas hibrida pada desain karakter visual yang digunakan di busana tujuh bidadari 7 Wonders yaitu berasal dari Indonesia, Jepang, Arab, Turki, India, Inggris era Victoria dan Romawi Kuno.
\end{abstract}

Kata Kunci: desain karakter, hibrida, komik, busana.

\begin{abstract}
Japanese comics become one of the mecca for reference in making comics, especially manga comics. Not a few Indonesian comics are so thick with mang a elements that it is difficult to distinguish Japanese comics from Indonesian comics if only viewed from their visual form. In addition to working on the style of Japanese manga drawings, not a few Indonesian comic artists have displaved characteristics on Indonesian visual character designs. A case in one of the Indonesian comics that is 7 Wonders comics. This study aims to determine the identity of a hybrid visual character design in one of the Indonesian comics, namely the 7 Wonders comics. This study uses a qualitative descriptive method approach that is by describing each obiect to be studied. The findings of this study indicate that the characters that have the most prominent hybrid elements are the 7 Wonders angel characters. The visual character design of the seven Wonders 7 nymphs has been deformed and the combination of two or more vi sual identities, both in fashion and in the character figure. The hybrididentity in the visual characterdesign used in the fashion of the seven Wonders 7 nymphsis originating from Indonesia, Japan, Arabia, Turkey, India, the Victorian era and Ancient Rome.
\end{abstract}

Keywords: character design, hybrids, comics, clothing

\section{PENDAHULUAN}

Pada komik Indonesia haru snya memiliki ciri khas asal Indonesia pada figurnya, dan gaya pada pakaian akan memberi kesan tertentu. Misalnyacirikhas pada wanita dari daerah jawa barat pada masa lampau seperti menggunakan pakaian kemben dengan motif batik daerahnya yang akan menunjukkan asal dari penggunanya. Namun pada komik 7 Wonders karya metalu ini karakteristik desain, bidadari-bidadari tak lagi hanya menggunakan kemben dan motif batik, membuat kesan hibrida terasa sangat pekat pada komiknya. Pakaian bidadari pada karya metalu ini masih melekatkan beberapa corak seperti kain batik tetapi pada desain pakaianny a sudah bercampur dengan desain pakaian dewa dewi as al Asia Timur khususnya Jepang. Seperti para dewa-dewi Jepang yang memiliki selendang mengambang berbentuk pola setengah lingkaran dipunggungnya untuk menunjukkan dia dapat melayang dan berada pada dimensi yang berbeda. Komik 7 Wonders yang diangkat dari cerita legenda Indonesia ini dikemas dengan manga Jepang. Perpaduan dari budaya yang divisual dikomik ini, peneliti ingin mengidentifikasi perpaduan budayayang terdapat pada komik 7 Wonders tersebut. Hal ini 
menarik perhatian peneliti karena merupakan bentuk dari dinamika dunia komik lokal kontemporer, dimana komik Indonesia saat ini mendapat keterpenganuhan dari berbagai style gambar komik dari luar negeri, salah satunya Jepang.

Studi media dan kajian desain yang berjudul "Tinjauan Karakteris tik Desain Hibrida Pada Komik 7 Wonders Karya Metalu Tahun 2016-2018" ini berawal dari ketertarikan peneliti untuk mendalami persoalan hibriditas pada komik 7 Wonders. Hibrida ditampilkan pada pakaian y ang sekilas tergambarkan dengan bentuk visual yang memiliki ciri khas Indonesia dan juga memiliki ciri khas negara lain. Bentuk visual yang dihadirkan komikus inilah yang membuat peneliti in gin menguraikan identitas hibrida yang diaplikasikan oleh komikus pada komik 7 Wonders ini.

Dengan penguraian identitas hibrida pada pakaian yang dikenakan karakter pada komik 7 Wonders maka penelitian ini bertujuan mengungkapkan sejauh mana karakteristik desain hibrida pada komik 7 Wonders karya Metalu.

\section{KAJIAN TEORI}

\section{Ilustrasi}

Salam (2017:1) mengungkapkan "Dewasa ini, seni ilustrasi telah mengalami perkembangan yang menjadikannya sulit untuk dipahami jika kita berpijak pada pengertian tradisional ilustrasi sebagai "gambar yang berfungsi untuk menjelaskan" Seni ilustrasi kontemporer tampil dalam bentuknya yang semakin variatif, tidak hanya berupa "gambar," menjadi subjektif-ekspresif, bahkan berwujud abstrak dalam corak dan tema, sehingga tidak lagi sejiwa dengan makna awal seni ilustrasi sebagai sesuatu yang memperjelas, sesuatu yang membuat konsep, benda, atau suasana menjadi terang-benderang. Sofyan Salam mengemukakan 3 esensi seni ilustrasi, yaitu: (1) berbagai perspektif dalammemaknai seni ilus trasi, (2) sebuah pendekatan dalam memahami esensi seni ilustrasi, dan (3) fungsi dari seni ilustrasi" (Salam, 2017:1-18).

Selanjutnya Wahana (2020: 195) memaparkan ilustrasi adalah media penyampaian pesan yang memiliki nilai tertentu. Gambar ilustrasi yang baik harus dapat menggambarkan dengan jelas pesan/hal yang ingin disampaikan atau dijelaskan. Dari pengertian ini ilustrasi kemudian diartikan sebagai sesuatu yang membuat jelas dan terang.

Dikutip dari artikel Gurupendidikan.com oleh Kurniawan, Fariz mengatakan (2009:14), ilustrasi
Gorga : Jurnal Seni Rupa

Volume 09 Nomor 02 Juli-Desember 2020 p-ISSN: 2301-5942 | e-ISSN: 2580-2380

adalah senagai bentuk ekspektasi dari ketidakmungkinan dan tak ada yang berbeda jauh seperti halnya angan-angan, yang sifatnya virtual atau maya, serta ilus trasi hadir dalam sebagai diverikasi. Gambar ilustrasi adalah gambar yang menceritakan atau memberikan penjelasan pada cerita atau naskah tertulis. Ilustrasi dalam perkembangan secara lebih lanjut ternyata tidak hanya berguna sebagai sarana pendukung cerita, tetapi juga dapat menghiasi ruang kong. Misalnyadalammajalah, koran, tabloid dan lainlain. Ilustrasi bis a berbentuk macam-macam, seperti karyaa seni, lukis, grafis, karikatural, dan akhir-akhir ini banyak dipakai image bitmap hingga karya foto (Soedars o, 2014:566).

Berdasarkan pendapat tersebut di atas, maka dapat disimpulkan bahwa ilustrasi adalah sebuah gambar yang mampu menceritakan suatu kejadian dengan ataupun tanpa bantuan teks.

\section{Komik}

Komik adalah sebuah narasi yang diceritakan melalui gambar yang diatur dalamgaris -garis horis ontal, setrip, atau kotak, yang dis ebut panel, dan dibaca seperti teks verbal dari kiri ke kanan. Komik biasanya menggambarkan petualang an satu karakter atau lebih dalam rangkaian waktu yang terbatas. Dialog yang direpresentasikan oleh kata-kata yang dilingkari di dalam balon yang dikeluarkan dari mulut atau kepala karakter yang berbicara. Sebagian besar gerakan diilustrasikan melalui penggunaan garis dari berbagai ukuran budaya populer s aat ini yang direfleksikan oleh komik, adalah sebuah narasi dalam dunia modern. Sebelum munculnya televisi, komik menentukan gaya berpakaian, gaya rambut, makanan, perilaku dan sikapsikap lainnya. Komik juga memberikan inspirasi pertunjukkan, musik, balet, film, serial radio dan televisi, lagu-lagu populer buku dan mainan" (Patricia, 2018:280)

McCloud (2002:9), komik adalah kumpulan gambar yang berfungsi unutk menyampaikan informasi atau menghasilkan respon estetik bagi yang melihatnya. Seluruh teks cerita dalam komik tersusun secara rapi dan saling berhubungan antara gambar (lambang visual) dengan kata-kata (lambang verbal). Gambar di dalam sebuah komik diartikan sebagai gambar-gambar statis yang tersusun secarata berurutan dan saling berkaitan antara gamabar yang satu dengan gambar yang lain sehingga membentuk sebuah cerita. Menurut Sudjana dan Rifai (2011), komik dapat dipergunakan sebagai bahan ajar berupa komik. Komik dapat dijadikan bahan ajar karena dapat mengefektifkan proses belajar mengajar, meningkatkan 
minat belajar siswa, dan menimbulkan minat apresiasi siswa.

Maka dapat disimpulkan bahwa komik adalah suatu cerita yang bertekanan pada gerak dan tindakan yang ditampilkan lewat urutan gambar yang dibuat secara khas dengan paduan kata-kata.

\section{Karakter}

Menurut Pratama (2010:2-3) Sulit menjelaskan secara definitif tentang character design, namun ada beberapa aspek yang bis a dipelajari dari character desing, y aitu : a Character design adalah salah satu bentuk ilustrasi yang hadir dengan konsep "manusia" dengan segala atributnya (sifat, fisik, profesi, tempat tinggal bahkan takdir) dalam bentuk yang beraneka rupa, bis a hewan, tumbuhan ataupun benda;benda mati, b). Secara vis ual character design sering disebut dengan istilah "kartun". Biasanya hadir dengan visual yang sangat sederhana bahkan terkesan abstrak. Bentuk terdiri dari garis-garis outline, penggunaan warna-warna solid dan aplikasi bentuk yang cenderung berlebihan (eksagration) yang ditujukan untuk mengkomunikasikan konsep karakter yang dimiliki. Hal ini tidak terikat bahkan relatif tergantung gaya apa yang dianut oleh si perancang. (Pratama, 2010:2-3).

Menurut Wibowo (2012: 33), bahwa karakter adalah cara berpikir dan berperilaku yang menjadi ciri khas tiap individu untuk hidup dan bekerja s ama, baik dalam lingkup keluarga, masyarakat, bangsa dan negara.

Menurut KBBI, karakteristik adalah sifat khas sesuai dengan perwatakan tertentu. Karakteristik adalah kualitas tertentu atau ciri khas dari seseorang atau sesuatu. Dalam ilmu biologi karakteristik seringkali dikaitkan dengan anatomi dan ciri khas dari hewan lainnya. Misalnya karakteristik capung adalah mempunyai sayapyang tipis. Begitu pula dengan figur dalam komik, masing masing figur memiliki Karakteristik yang berbeda, baik dari segi warna, potongan rambut, pakaian yang dikenakan, dan sebagainya, a). Karakteris tik adalah s esuatu yang khas atau mencolok dari seseorang ataupun sesuatu benda atau hal. Contoh karakteristik api adalah panas dan karakteris tik air adalah menyejukkan, b). Karakteris tik manusia dalamgeografi adalah fitur dan corak fasilitas di permukaan bumi yang dibuat oleh manusia. Ini termasuk bangunan, bendungan, jalan, dan lain-lain. Karakteris tik manusia dalambiologi adalah watak, dan sifat-sifat manusia yang mendasar. Ini termasuk ciri fisik, tindakan manusia dan sebagainya. Contoh karakteris tik bidadari kenanga adalah bidadari kuning, ia memakai pakaian dominan dengan warna kuning,
Gorga : Jurnal Seni Rupa

Volume 09 Nomor 02 Juli-Desember 2020

p-ISSN: 2301-5942 | e-ISSN: 2580-2380

rambut dan mata bewarna hijau, sedangkan karakteris tik pada bidadari azela adalah bidadari pink, pakaian yang dikenakan berwarna pink, warna rambut dan mata bewarna merah, dan bentuk rambut azela adalah lurus, tidak seperti kenanga yang memiliki rambut bergelombang.

Karakter adalah ciri khas yang dimiliki oleh suatu benda atau individu. Ciri khas tersebut asli dan mengakar pada kepribadian benda atau individu tersebut, dan merupakan mesin yang mendorong bagaimana seseorang bertindak, bersikap, berujar, dan merespon sesuatu.

\section{Hibrida}

Hibrida menurut KBBI memiliki arti linguistik yaitu kata kompleks y ang bagian-bagiannyaberasal dari asal yang berbeda. Istilah hibrida sendiri dipakai dalam banyak konteks seperti biologi, budaya, bahasa dan banyak lagi. Hibrida dari s egi ilmu Biologi, turunan yg dihasilkan dr perkawinan antara dua jenis yg berlainan (tentang hewan atau tumbuhan): pohon kelapa dapat berbuah pd usia empat tahun. Hibrida dari segi linguistik kata kompleks yg bagian-bagiannya berasal dari bahasa berbeda, seperti dwifungsi, antarjenis individu atau kelompok individu tumbuhan atau hewan yg merupakan hasil perkawinan silang atau individu yg berbeda jenisnya.

Hibrida dapat berarti hasil dari pencampuran atau penambahan dari duabudaya atau lebih yang disatukan dalam satu karya yaitu komik. Di Indonesia sendiri hibrida dalam komik sudah dimulai dari awal munculnya komik di Indonesia, yaitu perpaduan style dari berbagai negara seperti Amerika dan Jepang.

Terbitnya 7 Wonders sebagai bagian dari komik Indonesia yang mengadopsi dua identitas budaya berbeda bangsa, salah s atunya yaitu wayang (lokal) dan budaya Jepang, menjadikan komik ini memiliki identitas hibrida dalam gaya penyajiannya, di mana unsur wayang terdapat pada keterlibatan tokoh-tokoh populer wayang. Sedangkan unsur manga menonjol pada gaya gambar dan elemen visual.

\section{Desain Busana}

Dikutip dari jurnal Imaji dengan nama Asri (2007:177) "Pengertian desain menurut Chodijah dan Mamdy (1982) adalah suatu susunan darigaris, bentuk, warna, dan tekstur. Menurut Ariy anto (2003: 28) des ain adalah elemen desain busana secara lengkap yang terdiri atas garis arah, bentuk, ukuran, warna, nilai, dan tekstur. Asri (2007:179-180) juga mengutipkan "Menurut Kamil (1996: 9) desain busana adalah mencipta model pakaian. Yang dimaksud mencipta adalah 


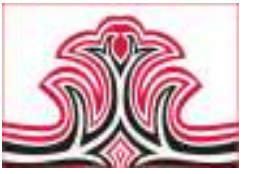

mengeluarkan perasaan yang kuat didorong oleh emosi, sehing ga menimbulkan atau membentuk sesuatu yang baru. Jadi, mencipta mode atau fashion design adalah membuat sesuatu yang baru tentang mode pakaian. Orang yang pekerjaanya mencipta mode disebut pencipta mode atau perancang mode. Tahapan atau langkah pembuatan desain busana seperti dikemukakan oleh Widarwati dkk (1994: 64) sebagai berikut: a). Menetapkan sumber ide yang akan dijadikan dasar pembutan desain busana, b). Menggambar perbandingan tubuh, posisi tubuh, sesuai model busana yang akan dibuat. Tentukan garis kes eimbangan, ganis pinggang, garis panggul, dan garis lutut tepat pada tempatnya, c). Menggambar bagianbagian busana sesuai dengan ide atau gagasan, d). Menghapus garisgaris pertolongan yang tidak diperlukan, sehingga tinggal garis desain yang diperlukan, dan e). Memberi tekstur pada desain, sehingga gambar kelihatan lebih hidup dan memberikan gambaran mengenai bahan yang digunakan.

Berdas arkan pengertian di atas, desain busana adalah rancangan busana yang dibuat berdasarkan unsur dan prinsip desain, dibuat berdasarkan langkah-langkah yang benar. Hal penting y ang dijadikan pedoman dalam mendesain busana adalah sumber ide.

\section{METODE PENELITIAN}

Metode penelitian yang digunakan dalampenelitian ini adalah metode penelitian deskriptif kualitatif. Dalam hal ini peneliti akan medeskripsikan hasil dari data-data yang dikumpulkan berdasarkan instrumen serta populasi dan sampel yang telah ditentukan. Penelitian ini dilakukan dengan lebih banyak memanfaatkan pendekatan kepustakaan, hal ini dilakukan karena objek penelitian berupa komik online sehingga dalam pencarian data atau informasi serta pengolahannya banyak bekerja secara online. Penelitian ini dilaksanakan pada bulan Desember 2019 sampai dengan bulan Febuari 2020 Dalam penelitian diperlukan metode pengumpulan data dengan teknik dan alat pengumpul data yang relevan. Penggunaan teknik dan alat pengumpul data yang tepat lebih memungkinkan untuk mendapatkan datay ang objektif. Adapun metode pengumpulan data yang digunakan, yaitu: observasi, kajian pustaka, dan pencarian online. Adapun langkah-langkah yang ditempuh oleh peneliti dengan menggunakan analisis kualitatif model interaktif adalah sebagai berikut: a). Mengamatikomik 7 Wonders karya metalu tahun 2016 - 2018, b). Melakukan identifikasi terhadap keterkaitan aspekaspek hibriditas yang disertakan pada komik itu, dan c). Melakukan pengklasifikasian mengenai desain karakter
Gorga : Jurnal Seni Rupa

Volume 09 Nomor 02 Juli-Desember 2020

p-ISSN: 2301-5942 | e-ISSN: 2580-2380

visual pada figur komik 7 Wonders kary a metalu tahun 2016-2018.

Untuk menetapkan keabsahan data diperlukan teknik pemeriksaan yang didasarkan pada sejumlah kriteria tertentu. Ada empat kriteria yang digunakan, yaitu 1) kredibilitas (derajat kepercayaan), 2) keteralihan (tranferbility), 3) kebergantungan (dependenbility), 4) kepastian (conformability), a). Kredibilitas data dalam penelitian ini peneliti lakukan dengan cara menemukan data dariberbagai sumber terkait komik 7 Wonders, b). Keteralihan (tranferbility) data dalam penelitian ini dilakukan penulis dengan melakukan pengumpulan data dari sumbernya langsung yaitu komik 7 Wonders karya Metalu di Webtoon dan artikel-artikel yang merujuk kepada komik 7 Wonders, c). Kebergantungan (dependenbility) data dalam penelitian ini dilakukan dengan cara melakukan konsistensi pada hal yang penting untuk mengetahui hibriditas karakter tersebut benar-benar dipengaruhi oleh kesukaan dari komikus dari komik jepang atau y ang lainnya, dan d). Kepastian (conformability) data dalam penelitian ini dilakukan dengan cara mengambil beberapa gambar atau karya yang benar-benar terdapat pada komik 7 Wonders mengandung unsur hibrida. 


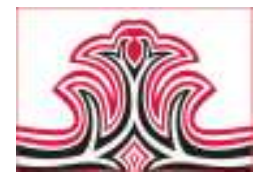

\section{HASIL DAN PEMBAHASAN}

\section{Hasil}

\section{1). Nama Karakter}

Tabel 1. Nama Karakter Komik 7 Wonder

\begin{tabular}{|c|c|c|}
\hline No. & Nama & Spesies \\
\hline 1. & Jaka & Mamusia, bidadara, iblit \\
\hline 2 & Kinanti & $\begin{array}{l}\text { Manusia dan bidadari } \\
\text { (bergayap hitam) }\end{array}$ \\
\hline 3. & Satya & $\begin{array}{l}\text { Manusia dan bidadara } \\
\text { (bersayap hitam) }\end{array}$ \\
\hline 4. & Sulkma & $\begin{array}{l}\text { Manusia dan bidadani } \\
\text { (bersayap hitum) }\end{array}$ \\
\hline 4. & Jaka Tarub & Mamusia \\
\hline 5. & Yonas & Manusia \\
\hline 6. & Deva & Mamusia \\
\hline 7. & Pandhu & Manusia \\
\hline 8. & Camira & Mamusia \\
\hline 9. & Ryan & Manusia \\
\hline 10. & Yance & Manusia \\
\hline 11. & Ria & Mamusia \\
\hline 12. & Rizaki & Manusia \\
\hline 13 & Dino & Mamusia \\
\hline 14. & Lavender & Bidadari \\
\hline 15. & Hotemesia & Bidadari \\
\hline 16 & Verbena & Bidaciani \\
\hline 17 & Amarilis & Bidadari \\
\hline 18. & Solda & Bidadani \\
\hline 19. & Azelea & Bidadari \\
\hline 20. & Orchid & Bidadari \\
\hline 21. & Lily & Bidaciani \\
\hline 22. & Dewasrani & Dewa \\
\hline 23. & Nawangwulan & Bidadañ \\
\hline 24. & Krisan & Bidadarí \\
\hline 25. & Raja Jorgun & Raja Iblis \\
\hline 26. & Doypleganger & Iin \\
\hline 27. & Liz & Iblis \\
\hline
\end{tabular}

\section{2). Posisi Karakteristik Hibrida}

Posisi visual karakteristik pada figur komik terbagi menjadi dua bagian yaitu karakteristik tubuh dan karakteristik busananya. karakteristik tubuh figur komik 7 Wonders memiliki hibrida genetika antara manusia dengan hewan (sayap yang dimiliki seekor burung)

\section{3). Karakter Visual pada Busana Bidadari}

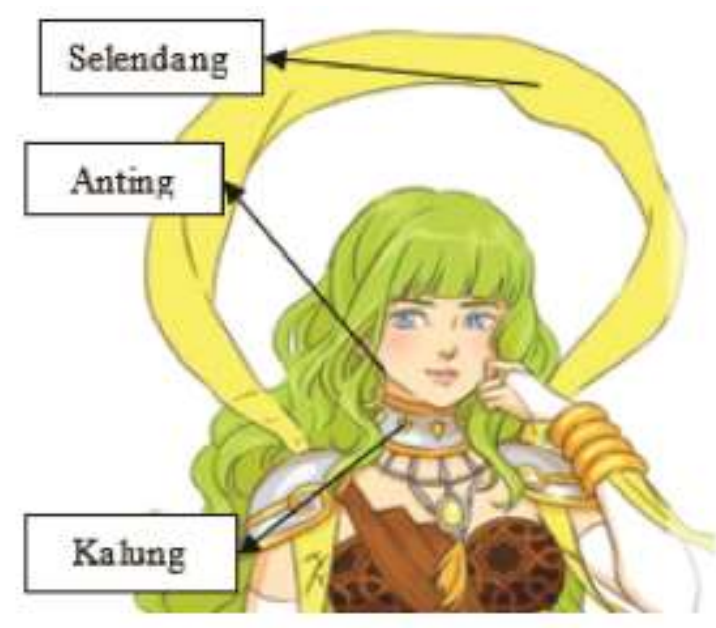

Gambar 1. Outfit pada Kepala Bidadari (Sumber: Komik Metalu 7 Wonder)

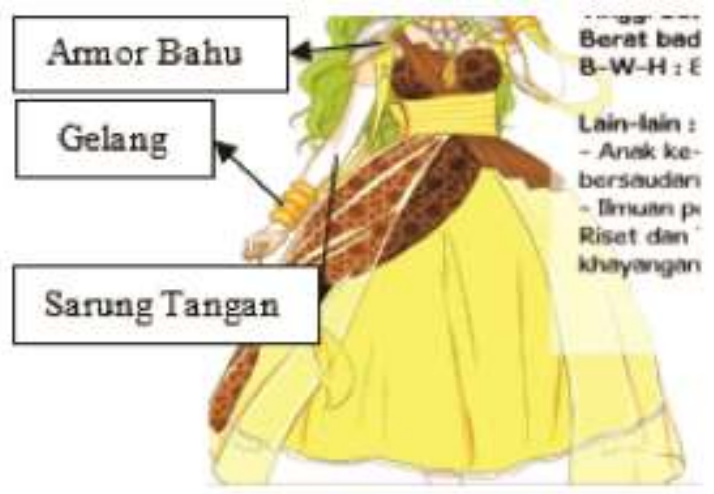

Gambar 2. Outfit pada Lengan Bidadari (Sumber: Komik Metalu 7 Wonder)

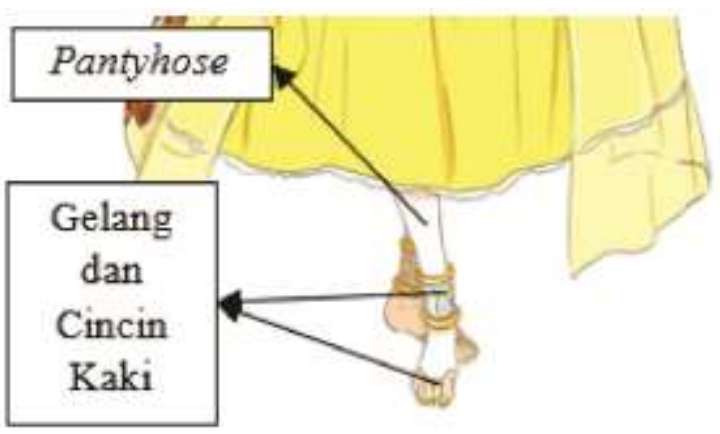

Gambar 3. Outfit pada Kaki Bidadari (Sumber: Komik Metalu 7 Wonder)

\section{Pembahasan}

\section{1). Karakter Figur Hibrida}

Setelah mengamati karakter figur komik 7 Wonders karya metalu, dapat kita lihat bahwa komik 7 Wonders menggunakan gay a gambar manga Jepang 2 dimensi. Sesuai dengan rumusan masalahan, figur yang memiliki karakteristik visual yang mengandung unsur hibrida adalah karakter para bidadari, karakter bidadani memiliki hibriditas yang paling banyak dibandingkan 
dengan karakter manusia dan karakter makhluk dunia hitam. Baik dari karakteristik wajah maupun busana yang dikenakannya.

\section{2). Posisi Karakteristik Hibrida}

Pada wajah karakter komik 7 Wonders s pesies manusia umumnya memiliki ciri khas wajah asia, yaitu: mata cenderung lebih gelap (coklat dan hitam), warna kulit tidak terlalu gelap maupun putih pucat dan memiliki rambut bewarna hitam. Untuk spesies bidadari/bidadaradan dewa/dewi memiliki warna mata yang berbeda dari orang asia karena mereka merupakan mahluk kahyangan, spesies bidadari/bidadara dan dewa/dewi memiliki beragam warna mata seperti warna spektrum pelangi, namun warna bidadari/bidadara tidak menetukan warna pada matanya, misalnya bidadari kuning (Kenanga) yang memiliki warna mata hijau. Para bidadari/bidadaradan dewa/dewi juga memiliki rambut berwarna-wami seperti warna pada matanya. Untuk warna kulit bidadari/bidadara dan dewa/dewi cenderung lebih pucat dibandingkan warna kulit pada spesies manusia. Yang terakhir merupakan spesies mahluk dunia hitam, Mahluk dunia hitam memiliki warna kulit lebih gelap, memiliki kuku panjang dan hitam, mata bewarna putih menyeluruh ataupun bewarna hitamdeng an lensamata yang lebih cerah.

Pos is i karakteris tik visual y ang dihibrida gen pada figur adalah spesies bidadari bidadara tingkat tinggi, dewa/dewi dan spesies dunia hitam. Dewa/dewi bidadari/bidadara memiliki hibrida genetik antara manusia dan sayap burung bewarna putih maupun bewarna hitam. mahluk dunia hitamdikas ta yang tinggi umumnya memiliki wujud hampir seperti wujud manusia, sedangkan mahkluk dikasta rendah dan menengah memiliki wujud beragam baik menyerupai bentuk hewan maupun berbentuk monster seluruhnya.

\section{3). Karakter Visual pada Busana Bidadari}

Desain selendang yang digunakan adalah selendang polos menyesuaikan dengan warna sosok bidadari tersebut, bidadari kuning menggunakan selendang kuning, bidadari merah menggunakan selendang merah, begitu seterusnya. namun bentuk selendang yang melingkar dan melay ang merupakan ciri khas dari dewa/dewi asal Asia Timur seperti dewa/dewi Tiongkok Jepang. Misalnya ilustrasi dari dewi bulan (Chang'e).

Kemudian pada telinga bidadari 7 Wonders terdapat anting tusuk dengan bentuk lingkaran berdiameter kurang lebih $5 \mathrm{~cm}$ dan berwarna sesuai dengan warna sosok bidadari tersebut, anting tusuk lingkaran ini
Gorga : Jurnal Seni Rupa

Volume 09 Nomor 02 Juli-Desember 2020

p-ISSN: 2301-5942 | e-ISSN: 2580-2380

merupakan desain anting yang cukup modis untuk dikenakan. Dikutip dari laman web Mediaone.id, Anting tertua berada di Mesopotamia. Anting dari masa $3500 \mathrm{SM}$ itu berbentuk cincin besar berpinggiran tipis. Model yang sama juga muncul pada awal berdirinya bangsa Yunani (2500-1600 SM). Melimpahnya persediaan emas membuat model anting yang muncul menjadi beraneka ragam, mulai dari bentukbulan sabit hing ga bentuk perahu lengkap dengan manusia sebagai penumpangnya. Pada 475-330 SM anting-anting gantung dengan panjang mencapai bahu menjadi popular. Sedangkan anting bentuk cincin banyak digemari di India dan Cina hingga abad ke 7.

Pada leher bidadari 7 Wonders, terdapat s ebuah kalung besar yang menjuntai hingga ke dadanya. Terdapat beberapa permata bewarna kuning menghiasi kalungnya tersebut. Saat melihat kalung permata denganukuran y ang cukup lebar, hal pertama kali yang terpintas kalung para penari India. Wanita India memang menarik dengan segala atributnya. Sama seperti wanita dari negara lain yang juga memiliki keunikan sendiri dari negaranya. Yang paling menonjol bis a kita lihat dariwanita India adalah aneka pemiasan dan aksesoris yang mereka kenakan. Perhatikan gambar berikut, kalung yang dikenakan oleh wanita India.

Pada bahu Bidadari 7 Wonders terdapat lempengan armor bahu, pakaian armor disebut juga sebagai baju zirah merupakan pakaian pelindung yang dikenakan untuk berperang. Baju zirah lempeng diidentikkan dengan ksatria-ksatria eropa. Salah s atu baju zirah yang indah adalah baju zirah yunani klasik yang dibentuk menyerupai otot dada dan perut, banyak digunakan oleh petinggi dan bangsawan Yunani dan Romawi. Terdapat empat buah gelang dengan ukuran yang cukup besar pada kedua tangan bidadari 7 Wonders, sehinggatampak seperti memenuhi tangannya tersebut. Warna gelang tersebut dis esuaikan dengan warna dari bidadarinya. Ciri khas wanita y ang mengenakan gelang yang cukup lebar dikedua tangannya merupakan ciri khas dari wanita India.

Bidadari 7 Wonders mengenakan sarung tangan bewarna putih polos yang menutupi kedua lengannya. Ciri khas wanita yang mengenakan sarung tangan panjang tersebut merupakan ciri khas wanita-wanita pada era Victoria. Para bangsawan Ing gris sering sekali mengenakan sarung tangan menambahkan kesan keanggunan.

Istilah 'pantyhose' berasal dari Amerika Serikat, merujuk pada gabungan panties (istilah AS untuk 
celana dalam wanita) dengan kaus nilon. Terdapat juga pantyhose untuk pria. Pantyhose pria lebih elastis dan panjang, Bias anya dikenakan oleh joki kuda di bawah kaus kaki suteranya. Beberapa nelayan juga mengenakannya untuk melawan hewan laut.

Gelang kaki yang terdapat pada kaki karakter bidadari 7 Wonders tersebut tampak memiliki ukuran cukup lebar. meski telah di modifikasi, wanita yang menggunakan gelang pada kakinya sangat mirip dengan gelang yang dikenakan oleh penari Kathak asal India. Gerakan tari Kathak dikenal dengan istilah tatkar (gerakan kaki yang cepat) dan chakkar (gerakan memutar).

\section{KESIMPULAN DAN SARAN \\ 1.Kesimpulan}

Berdas arkan rumusan mas alah, hasil, pembahasan dan temuan penelitian khususnya tentang terkait dengan a) Nama dan figur hibriditas visual, b) karakter hibriditas visual dan c) karakter visual bu sana, maka disimpu lkan sebagai berikut : a). Nama dan figur-figur hibriditas karakter visual dalam komik 7 Wonders pada season satu tahun 2016-2018 yang paling menonjol adalah Jaka, Kinanti, Satya, Sukma, Kenanga, Jaka Tarub, Yonas, Deva, Pandhu, Candra, Ryan, Bangun, Bos Yance, Ria, Rizki, Dino, Lavender, Hortensia, Verbena, Amarilis, Sokka, Azelea, Krisan, Bidadan Nawangwulan, Raja Jorgun VII, Liz, Doppleganger, b). Hibriditas Karakter visual pada komik 7 Wonders terletak pada posisi hibrida genetik dan hibrida identitas busana, dan c). Identitas karakteris tik visual bus ana bidadari komik 7 Wonders adalah Tiongkok, Jepang, Indonesia, Arab, Inggris (era Victoria), India, Yunani, Amerika Serikat, Timur Tengah.

\section{Saran}

Temuan tentang Nama dan Figur-figur hibriditas karakter visual dalamkomik 7 Wonders ternyata sangat menarik dan penting untuk dikaji lebih lanjut terkait budaya Indonesia maka peneliti meny arankan bagi: a). Komikus agar dapat membuat nama dan figur yang lebih sesuai dengan karakter Indonnesia, b). Bagi masyarakat atau pembaca dapat mencermati dan mengambil pentingnya nama dan figur karakter yang sesuai dengan karakter Indonesia, dan c). Bagi Peneliti agar dapat meneliti lebih lanjut tentang respon atau dapat hibriditas terkait nama dan figur.

Temuan tentang hibrida karakteristik visual figur komik 7 Wonders ternyata sangat menarik dan penting untuk dikaji lebih lanjut terkait dengan komik asal budaya Indonesia maka peneliti meny arankan bagi: a). Bagi komikus agar dapat lebih berkreasi dalam penciptaan sebuah karakter komik, b). Bagi mas yarakat
Gorga : Jurnal Seni Rupa

Volume 09 Nomor 02 Juli-Desember 2020 p-ISSN: 2301-5942 | e-ISSN: 2580-2380

atau pembaca diharapkan lebih mengapresiasikan karakter-karakter figur dan komik-komik Indonesia, dan c). Bagi peneliti agar dapat meneliti lebih lanjut mengenai hibrida karakter pada figur komik Indonesia.

Temuan tentang identitas hibrida pada busana figur komik 7 Wonders ternyata s angat menarik dan penting untuk dikaji lebih lanjut terkait dengan komik asal budaya Indonesia maka peneliti menyarankan bagi: a). Bagi komikus agar lebih menonjolkan karakteristik identitas bus ana Indonesia pada komiknya, b). Bagi mas yarakat dan pembaca agar tetap meles tarikan gaya busana khas Indonesia dan daerahnya, dan c). Bagi peneliti diharapkan dapat meneliti lebih lanjut mengenai identitas busana Indonesia.

\section{DAFTAR RUJUKAN}

Asri, N. (2007). Peningkatan Kreatifitas Seni Dalam Desain Busana. Imaji. 5 (2).173-184.

Halawa, W.E., Triy anto, R., Budiwiwaramulja, D., \& Azis, A. C. K. (2020). Analis is Gambar Ilustrasi Hombo Batu Nias Gunung sitoli. Gorga: Jurnal Seni Rupa, 9(1), 193-203.

Kurniawan, Aris . (2020). Pengertian Ilustrasi Menurut Para Ahli Serta Sejarah, Fung si Dan Tujuannya. Diunduh pada 1 oktober 2020. [Online] di https://www.gurupendidikan.co.id/ilustrasi/.

McCloud, S. (2002). Understanding Comic. Jakarta: Gramedia.

Metalu. (2016). 7 Wonders. Diunduh pada 20 Januan $2020 . \quad$ [Online]. di https://www.webtoons.com/id/fantasy/7wonders/list?title_no=699.

Patricia, F.D. (2018). Analis is Semiotika Komunikasi Visual Buku Memahami Komik Scott McClott. Jurnal Studi Komunikasi. 2(2). 278289.

Pratama, R. (2010). Materi Character Design. Diunduh pada 22 Desember 2019. [Online]. di https://ranggawahyudiarta-wordpresscom.cdn.ampproject.org/v/s/rang gawahyudia rta.wordpress.com/2011/01/05/matericharacterdesign/amp/?usqp=mq331AQFKAGwASA\% 3D\&amp_js_v $=0.1 \#$ aoh $=16016287607910 \& r$ eferrer=https $\% 3 \mathrm{~A} \% 2 \mathrm{~F} \% 2 \mathrm{Fwww}$.google.com \&amp_tf=Dari\%20\% 251\%24s \&ampshare $=\mathrm{ht}$ tps $\% 3 \mathrm{~A} \% 2 \mathrm{~F} \% 2 \mathrm{Frang} g a w a h y u d i a r t a . w o r d p r e$ s s.com\%2F2011\%2F01\%2F05\%2Fmatericharacterdesign\%2Famp\%2F\%23aoh\%3D160162876 $07910 \% 26$ referrer\%3Dhttps $\% 253 \mathrm{~A} \% 252 \mathrm{~F} \%$ 


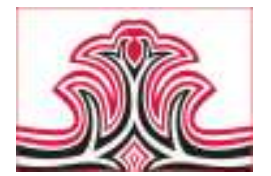

252Fwww.google.com\%26amp_tf\%3DDari $\% 2520 \% 25251 \% 2524 \mathrm{~s} \% 26 \mathrm{ampshare} \% 3 \mathrm{Dhtt}$ ps $\% 253 \mathrm{~A} \% 252 \mathrm{~F} \% 252 \mathrm{Frang}$ gawahyudiarta.w ordpress.com $\% 252 \mathrm{~F} 2011 \% 252 \mathrm{~F} 01 \% 252 \mathrm{~F} 05$ $\% 252$ Fmateri-character-design $\% 252 \mathrm{~F}$.

Salam, S. (2017). Seni Ilustrasi. Makasar: Badan Penerbit UNM.

Soedarso, Nick. (2014). Ilustrasi Perjalanan Mahapahit Gajah Maja. Jakarta Barat: Binus University.

Sudjana, N. \& A. Rivai. 2011. Media Pengajaran. Jakarta: Sinar Baru Algesindo.

Wibowo, Agus. (2012). Pendidikan Karakter: Strategi Membangun KarakterBangsa Berperadaban. Yogyakarta: Pustaka Pelajar.

Widarwati, S., Widjiningsih, Khayati, E.Z. (1994), Kontruksi Pola Busana. Yogyakarta : FPTK IKIP Yogyakarta. 